
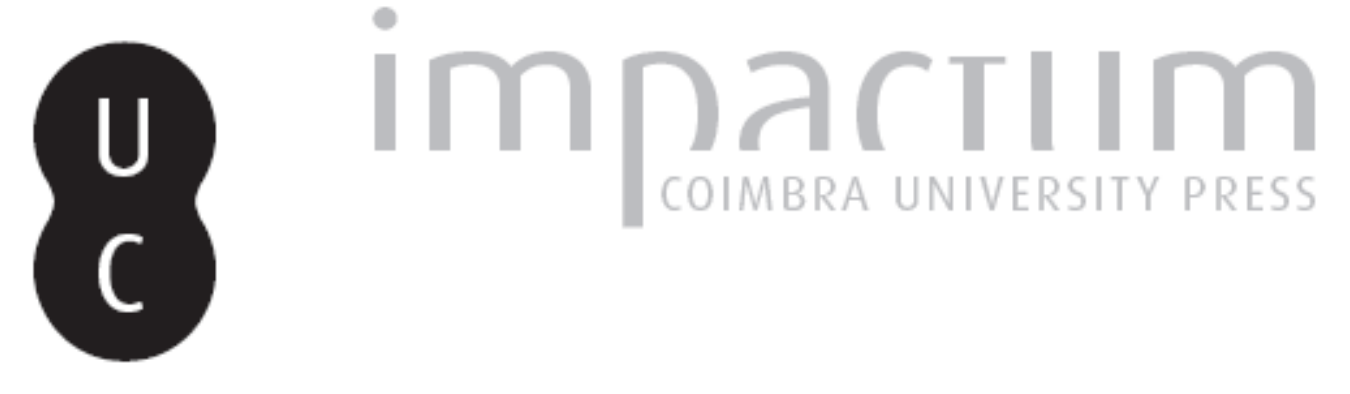

O rural e o urbano nas freguesias de Coimbra nos séculos XIII e XIV
Autor(es):
Campos, Maria Amélia Álvaro de
Publicado por: Instituto de História Económica e Social, Faculdade de Letras da Publicado por: Universidade de Coimbra

URL

DOI: $\quad$ DOI:http://dx.doi.org/10.14195/0870-4147_41_6

Accessed : $\quad$ 26-Apr-2023 06:13:15

A navegação consulta e descarregamento dos títulos inseridos nas Bibliotecas Digitais UC Digitalis, UC Pombalina e UC Impactum, pressupõem a aceitação plena e sem reservas dos Termos e Condições de Uso destas Bibliotecas Digitais, disponíveis em https://digitalis.uc.pt/pt-pt/termos.

Conforme exposto nos referidos Termos e Condições de Uso, o descarregamento de títulos de acesso restrito requer uma licença válida de autorização devendo o utilizador aceder ao(s) documento(s) a partir de um endereço de IP da instituição detentora da supramencionada licença.

Ao utilizador é apenas permitido o descarregamento para uso pessoal, pelo que o emprego do(s) título(s) descarregado(s) para outro fim, designadamente comercial, carece de autorização do respetivo autor ou editor da obra.

Na medida em que todas as obras da UC Digitalis se encontram protegidas pelo Código do Direito de Autor e Direitos Conexos e demais legislação aplicável, toda a cópia, parcial ou total, deste documento, nos casos em que é legalmente admitida, deverá conter ou fazer-se acompanhar por este aviso. 



\section{O rural e o urbano nas freguesias de Coimbra nos séculos XIII e XIV*}

Resumo:

A cidade medieval portuguesa exibia uma multiplicidade de estruturas e equipamentos necessários à subsistência dos seus habitantes, que lhe conferiam uma paisagem plural em que conviviam elementos rústicos e urbanos.

Neste estudo, reflectimos sobre os elementos denunciadores desta realidade e analisamos a forma como ela se materializava em Coimbra e enquadrava no contexto nacional coevo. Tendo por base os mais recentes trabalhos sobre esta cidade e a documentação neles publicada, fazemos uma interpretação da paisagem, percorrendo as suas paróquias nos séculos XIII e XIV, não nos detendo nos repetidos e comuns equipamentos habitacionais, mas nas demais estruturas funcionais e utilitárias que compunham o seu tecido urbanístico e socio-económico.

\section{Palavras chave:}

Idade Média; Paisagem Urbana; Cidade medieval; Coimbra.

\author{
Maria Amélia Álvaro de Campos \\ MARIA AMÉLIA ÁlVARO DE CAMPOS
Doutoranda na Universidade de Coimbra \\ Bolseira da Fundação para a Ciência e Tecnologia \\ melicampos@gmail.com
}

\begin{abstract}
:
The medieval Portuguese towns displayed a multiplicity of structures and equipment necessary for the subsistence of its inhabitants, that gave them a plural landscape where rural and urban elements lived together.

In this paper, we argue on the elements denouncing this situation and explore how it would materialize in Coimbra and how it was framed by the national context of the time. Based on the latest works about this town, and the set of documents published on them, we make an interpretation of the landscape, going through its parishes in the 13th and 14th centuries; we do not focus on its repeated and usual housing equipment, but on other functional and utilitarian structures that made up its urbanistic and social-economic network.
\end{abstract}

Keywords:

Middle-Ages; Urban Landscape; Medieval Town; Coimbra.

* O texto que aqui se apresenta tem por base a comunicação proferida no IV Congresso de Estudos Medievais, Coexistência e Cooperação na Idade Média, organizado pela Federação Internacional de Estudos Medievais em Palermo nos dias 23 a 27 de Junho de 2009, no âmbito da sessão Urbanismo e Paisagem. Porém, esse trabalho foi submetido a alterações substanciais, quer ao nível da sua estrutura, quer no âmbito da fundamentação bibliográfica que o suporta. Reformulações que contaram com o contributo dos avaliadores externos desta revista, a quem muito agradecemos. 
A cidade portuguesa da Baixa Idade Média denotava traços urbanísticos que lhe ficaram das sucessivas ocupações a que foi sujeita ${ }^{1}$. Ocupações estas que, protagonizadas por povos com sistemas políticos, modelos culturais e religiosos profundamente distintos, a marcaram, não só pela construção de novas estruturas, mas também pela demolição e transformação daquelas por elas encontradas. De facto, a herança da romanização foi vítima de fortes destruições perpetradas pelos povos invasores vindos do Norte da Europa no século $\mathrm{V}$ e as estruturas da cidade islâmica foram apagadas, de forma consciente e sistemática, pela posterior ocupação cristã ${ }^{2}$.

$\mathrm{O}$ processo da Reconquista deixou marcas estruturais na diferenciação entre os povoamentos urbanos do Norte e Centro do país relativamente aos meridionais. Assim, nesse primeiro espaço encontramos as cidades da reconquista asturiana, sedes episcopais, onde a arquitectura deixava lembrar a presença romano-visigótica. A Sul, situam-se os núcleos moçárabes, nos quais também reconhecemos a sobrevivência dessas estruturas arquitectónicas, mas onde o urbanismo estava marcado pelo domínio muçulmano. Na verdade, os moçárabes personificaram a síntese das várias ocupações, quer pela preservação dos anteriores modelos, quer pela assimilação das novas influências ${ }^{3}$. O grupo das cidades de maior presença moçárabe caracterizava-se, normalmente, por uma superior força económica e demográfica, denunciadora de um impulso dinamizador contínuo ${ }^{4}$.

Particularizemos o caso da cidade que nos propomos estudar. Coimbra fixou-se no ponto mais alto da colina sobranceira ao Mondego ${ }^{5}$, local estratégico por

1 Cfr. Jorge Gaspar, "A cidade portuguesa na Idade Média. Aspectos da estrutura física e desenvolvimento funcional”, in La Ciudad Hispanica Durante Los Siglos XIII al XVI, vol. I, Madrid, Universidad Complutense, 1985, p. 133.

2 Ver Luísa Trindade, Urbanismo na composição de Portugal, Coimbra, Faculdade de Letras, 2009 (tese de doutoramento policopiada), pp. 43 e 69. Os conquistadores cristãos apressaram-se a eliminar da paisagem as grandes construções da cidade islâmica, tanto mais que estas representavam um sistema politico e religioso a anular. Ver Christophe Picard, Le Portugal Musulman (VIII'-XIII ${ }^{e}$ siècle). L'occident d'al-Andalus sous domination islamique, Paris, Maisonneuve et Larose, 2000, p. 246.

3 Ver José Mattoso, "Moçárabes", in Fragmentos de uma composição medieval, Lisboa, Estampa, 1993, pp. 19-34.

4 Destacam-se desse grupo Coimbra, Lisboa e Santarém. Cfr. Saul António Gomes, "Mundo Rural e Mundo Urbano", in Joel Serrão e A. H. de Oliveira Marques (dir.), Nova História de Portugal, vol. III, Armando Luís de Carvalho Homem e Maria Helena da Cruz Coelho (coord.), Portugal em Definição de Fronteiras, Lisboa, Presença, 1996, pp. 391 e 392.

5 Os principais núcleos urbanos portugueses implantaram-se em lugares altos e nas proximidades de um rio que funcionava, simultaneamente, como barreira natural de protecção 
onde os romanos ${ }^{6}$ fizeram passar a via militar de Olisipo a Bracara Augusta. Devido às suas favoráveis características defensivas, na segunda metade do século $\mathrm{VI}^{7}$, foi alvo da transferência da sede diocesana de Conímbriga, da qual recebeu o nome ${ }^{8}$. Nos inícios do século VIII, a cidade foi conquistada pelos muçulmanos que aí se fixariam até 878 , ano da primeira conquista cristã, por Afonso III de Leão. Em 987, no decurso da ofensiva de Al-Mansur, Coimbra tornava a ficar sob o domínio do Islão ${ }^{9}$ até 1064 , data da sua reconquista definitiva, sob o comando militar de Fernando Magno ${ }^{10}$.

Este período de intermitência entre épocas de ocupação cristã e muçulmana foi profundamente marcante no que diz respeito ao espaço físico da urbe e à sua personalidade social e cultural. Na verdade, localizada no centro de Portugal, Coimbra é, simultaneamente, uma cidade episcopal ${ }^{11}$ do tempo romano-visigótico e uma cidade moçárabe, onde muitos dos lugares de culto sobreviveram em tempos de ocupação islâmica.

e elemento potenciador do desenvolvimento económico. Cfr. Orlando Ribeiro, "Cidade", in Joel Serrão (dir.), Dicionário de História de Portugal, vol. II, Porto, Livraria Figueirinhas, 1985.

6 É provável que o povoamento de Coimbra remonte a período anterior aos romanos. Ver Jorge de Alarcão, "As Origens de Coimbra”, in Actas das I Jornadas do Grupo de Arqueologia e Arte do Centro, Coimbra, 1979, p. 25.

7 As fontes conhecidas não permitem a definição de uma data precisa para esta transferência, no entanto, a maioria dos autores apontam para os finais do século VI. Ver, por exemplo, Maria do Rosário Morujão, A Sé de Coimbra: a Instituição e a Chancelaria (1080-1318), Lisboa, Fundação Calouste Gulbenkian e Fundação para a Ciência e Tecnologia, 2010, pp. 31-32.

8 Anteriormente, era designada por Aeminium, nome que permanece até pelo menos ao século VII, pois conhecem-se moedas cunhadas por reis visigóticos que apresentam este topónimo. Ver Jorge de Alarcão, A Montagem do Cenário Urbano, Coimbra, Imprensa da Universidade, 2008, p. 29. Segundo Christophe Picard não é impossível que tenha sido a chegada dos árabes a impor a transferência definitiva do topónimo. Ver Christophe Picard, Le Portugal Musulman..., cit., p. 182.

9 Importa referir que, durante o domínio islâmico, Coimbra funcionou como centro de poder económico e fiscal ao qual se vinculavam várias fortalezas implantadas nos seus arredores e na Serra da Estrela. O seu lugar dominante na região advinha-lhe da importância da sua localização estratégica e por ser sede de residência do $q \bar{a}$ ' $i d$. Ver Christophe Picard, Le Portugal Musulman..., cit., pp. 150 e 218.

${ }^{10}$ Cfr. Ângela Beirante, “A Reconquista Cristã”, in Joel Serrão e A. H. de Oliveira Marques (dir.), Nova História de Portugal, vol. II, A. H. de Oliveira Marques (coord.), Das Invasões Germânicas à Reconquista, Lisboa, Presença, 1993, pp. 259-264.

${ }^{11}$ Sobre o urbanismo das cidades episcopais ver Pilar Martínez Taboada, "Desarrollo urbanístico de las ciudades episcopales: Siguenza en la Edad Media", in La Ciudad..., cit., vol. II, pp. 957-972 e Anísio Miguel de Sousa Saraiva, “A inserção urbana das catedrais medievais portuguesas: O caso da catedral de Lamego", Revista Portuguesa de História, XXXVI, 1 (2002-2003) pp. 241-265. 
No período em que Portugal se começava a projectar como reino independente face às outras monarquias peninsulares, Coimbra ganhou uma particular preponderância política quando foi escolhida por D. Afonso Henriques para sua residência e sede da corte ${ }^{12}$. Todavia, tal facto não foi o único a defini-la como primeira capital do reino, acresciam-lhe ainda as características do seu tecido social, do seu desenvolvimento económico e da sua morfologia urbana ${ }^{13}$.

Com a progressão da Reconquista, porém, a centralidade de Coimbra começou a ser ameaçada pela anexação de outros importantes centros urbanos, como Lisboa e Santarém. No reinado de D. Afonso III, no qual se conclui este processo, Coimbra perdeu definitivamente a primazia de principal centro de poder político, na medida em que a corte passou a estanciar, durante iguais ou maiores períodos de tempo, naquelas duas cidades ${ }^{14}$. Deste modo, pronunciava-se «uma nova geografia dos centros de poder» ${ }^{15}$ e a cidade do Mondego foi, a médio prazo, desprovida das estruturas que nela sustentavam a sediação da corte, facto que, entre outras consequências, trouxe, como veremos, transformações à sua configuração urbana.

Em síntese, se na entrada da segunda metade do século XII, Coimbra surgia como a maior cidade portuguesa ${ }^{16}$, no início do último quartel do século XIV, era a Lisboa que cabia essa distinção. Na paisagem nacional deste período, o núcleo urbano conimbricense aparecia já num grupo de cidades mais pequenas, ultrapassado também por Évora, Santarém e Porto ${ }^{17}$.

Do ponto de vista do seu urbanismo, configuravam-se dois espaços urbanos distintos: o da cidade amuralhada ${ }^{18}$ - a Almedina - implantada na colina,

${ }^{12}$ Ver José Mattoso, D. Afonso Henriques, Lisboa, Temas e Debates, 2007, pp. 105-111. Esta transferência ocorreu em 1131 e, nas palavras do autor (p. 106), «ao resolver mudar-se para Coimbra, Afonso Henriques tomou a sua decisão mais transcendente para a sobrevivência de Portugal como nação independente».

${ }^{13}$ Ver Walter Rossa, Divercidade. Urbanografia do espaço de Coimbra até ao estabelecimento definitivo da Universidade, Coimbra, Faculdade de Ciências e Tecnologia, 2001 (tese de doutoramento policopiada), p. 418.

${ }^{14}$ Ver Leontina Ventura, D. Afonso III, Lisboa, Círculo de Leitores, 2006, pp. 164-172.

15 Ver Ibidem, p. 166.

${ }^{16}$ Em 1150, cidade de Coimbra apresentava cerca de 49 hectares, dos quais 22 correspondiam à área delimitada pelas muralhas. Cfr. Saul António Gomes, "Mundo Rural...", cit., p. 393.

${ }^{17}$ Cfr. A. H. de Oliveira Marques, "As Cidades Portuguesas nos Finais da Idade Média", Penélope. Fazer e Desfazer a História, 7 (1992) pp. 28 e 29.

18 A data da construção da muralha de Coimbra tem sido problematizada por vários autores: Jorge de Alarcão considera que esta pode remontar aos inícios do século IV, tendo sido alvo de profundas reconstruções posteriores. Cfr. Jorge de Alarcão, “As Origens...”, cit., p. 37; Sobre as muralhas e o castelo de Coimbra, ver Idem, Coimbra. A Montagem ..., cit., pp. 193-267. 


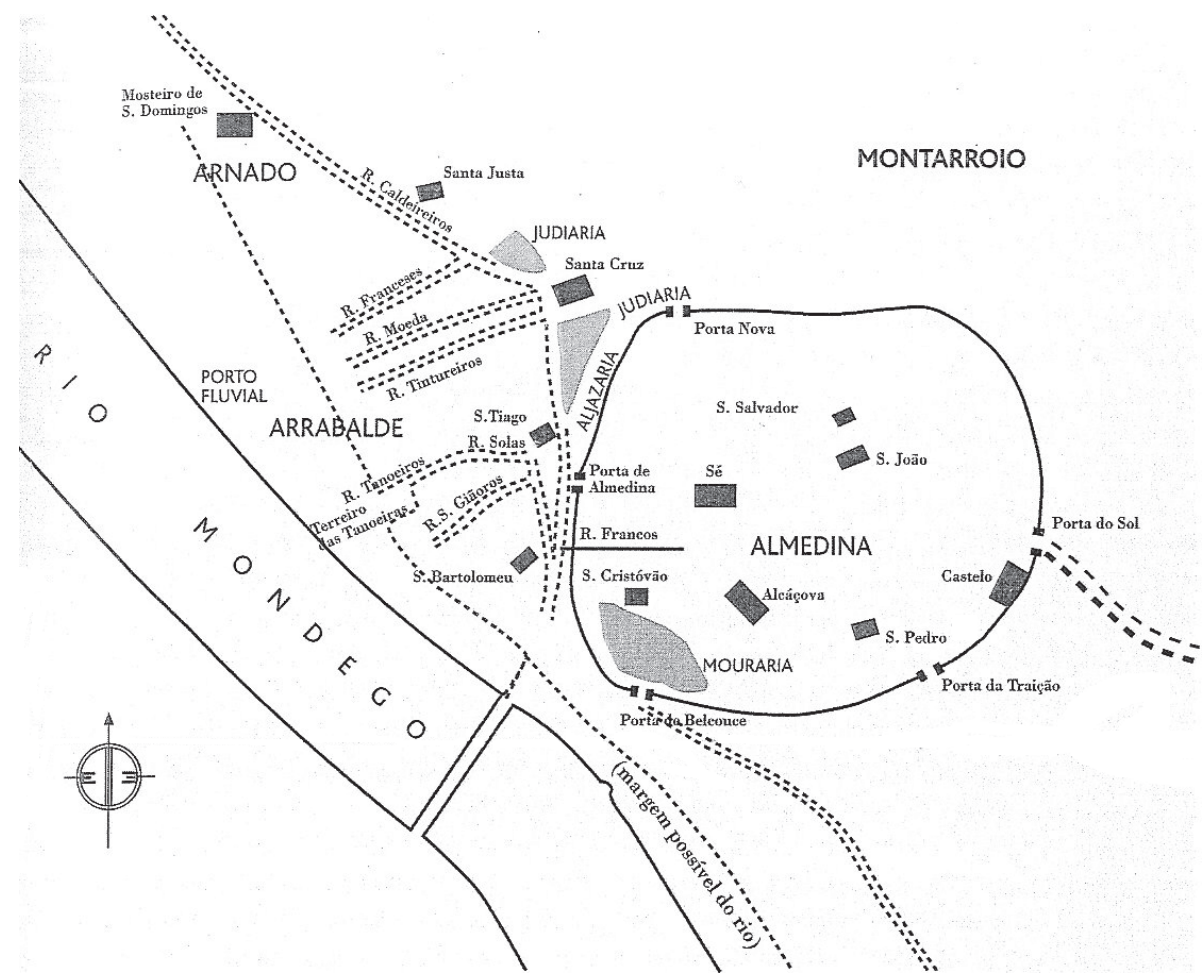

Mapa de Coimbra na Idade Média (segundo Jorge Alarcão)

e os arrabaldes ${ }^{19}$ que, a partir das portas da cidade ${ }^{20}$, se estruturavam em torno das igrejas paroquiais. Focos de povoamento polarizados em torno de um templo religioso, as paróquias medievais funcionavam, não só como células de espiritualidade, mas também como unidades de enquadramento socioeconómico $^{21}$.

${ }^{19}$ Mesmo antes do espaço intramuros estar completamente ocupado, as portas da cidade começaram a determinar novos focos de povoamento, nos finais do século XI: ver Leontina Ventura, "Coimbra Medieval: Uma cidade em formação", in Adília Alarcão (coord.), Inventário do Museu Nacional Machado Castro. Colecção de Ourivesaria Medieval. Séculos XII-XIV, Lisboa, Instituto Português de Museus, 2008, p. 17.

${ }^{20}$ Sobre as portas da muralha medieval de Coimbra, ver Jorge de Alarcão, Coimbra. A Montagem ..., cit., pp. 203-244 e Leontina Ventura, "A Muralha Coimbrã na Documentação Medieval”, in Actas das Ias Jornadas..., cit., pp. 43-55.

${ }^{21}$ Vários núcleos urbanos que se distinguiam, não só pelos níveis orográficos, como também pelas características dos seus habitantes: ver Saul António Gomes, "Coimbra: Aspectos da Sua 
No primeiro espaço, tinham lugar os edifícios do poder régio e militar - a alcáçova e o castelo -, os símbolos do poder religioso - como a Sé Catedral ${ }^{22}$ e os paços episcopais - e, mais tarde, aqui se implantou, por dois períodos, - de 1308 a 1338 e de 1354 a 1377 - a Universidade ${ }^{23}$, bastião de ensino e cultura. Era, ainda, nesta área intramuros, que se reunia o poder municipal, protagonizado pelos funcionários e homens bons do concelho ${ }^{24}$.

Os arrabaldes, por oposição com a cidade Alta, afiguravam-se como a cidade laboral, onde se animavam os mesteres ${ }^{25}$, se realizavam as trocas comerciais ${ }^{26}$ e onde a cidade se permeabilizava à influência do mundo rural envolvente ${ }^{27}$. A malha do casario urbano organizava-se, aqui como na Almedina, em torno das igrejas paroquiais, mas nestes arrabaldes, seriam determinantes as implantações dos vários mosteiros da cidade.

Data de 1131 o primeiro documento relativo ao Mosteiro de Santa $\mathrm{Cruz}^{28}$ que, situado no ponto de confluência dos principais eixos de crescimento do arrabalde citadino, cedo se tornaria um dos principais poderes religiosos de

Paisagem Urbana em Tempos Medievos”, Biblos, IV (2006) p. 134. Para uma melhor compreensão do espaço aqui descrito, aconselha-se a observação do mapa de Coimbra Medieval.

${ }^{22}$ Sobre a Sé de Coimbra no período medieval, ver Maria do Rosário Morujão, $A$ Sé de Coimbra..., cit.

${ }^{23}$ Para um enquadramento da conjuntura política, cultural e económico-social da cidade, nestes períodos de estância do Estudo Geral em Coimbra, ver Maria Helena da Cruz Coelho, “Coimbra Trecentista a Cidade e o Estudo", Biblos, LXVIII (1992) pp. 335-356.

${ }^{24}$ Sobre o governo concelhio de Coimbra, instituído pelo Conde D. Henrique (1111) e confirmado pelo seu filho (1179) com a promulgação de dois forais, ver Maria Helena da Cruz Coelho, "A propósito do foral de Coimbra de 1179", in Homens, Espaços e Poderes. Séculos XI-XVI, vol. I, Notas do Viver Social, Lisboa, Livros Horizonte, 1990, pp. 105-120. Quanto à localização das reuniões do concelho, temos notícia, já no século XIV, de que estas se fariam num paço perto da Sé. De 1378, chegou até nós um registo que refere uma torre da vereação, por certo a Torre da Almedina: Ver Idem, "Coimbra Trecentista...", cit., p. 337 e n. 6.

${ }^{25}$ Ver Idem, "Coimbra Medieval: uma cidade em maturação", in Adília Alarcão (coord.), Inventário do Museu..., cit., p. 36: «... pedreiros, carpinteiros, ferreiros e alfagemes, tecelões e alfaiates, tosadores e cordoeiros, curtidores ou sapateiros, oleiros e tanoeiros».

${ }^{26}$ A dinâmica comercial de Coimbra baseava-se na troca de produtos alimentares, de vestuário, calçado, marroquinaria e ourivesaria: ver Saul António Gomes, "Coimbra: Aspectos...", cit., p. 126.

${ }^{27}$ Ver Maria Helena da Cruz Coelho, "Coimbra Medieval:...”, cit., p. 36: «Almuinhas, vinhas e olivais verdejavam no anel próximo de Coimbra, logo se lhes seguindo boas terras aluviais nas margens do Mondego». Para um enquadramento da ruralidade e dinâmica socioeconómica da região de Coimbra e Baixo Mondego no período tardo-medieval, ver: Idem, O Baixo Mondego nos Finais da Idade Média, Lisboa, Imprensa Nacional - Casa da Moeda, 1989.

${ }^{28}$ Sobre a fundação e história deste mosteiro no período medieval, ver Armando Alberto Martins, O Mosteiro de Santa Cruz de Coimbra na Idade Média, Lisboa, Centro de História da Universidade, 2003. 
Coimbra. Em 1219, no extremo Nordeste da urbe, era fundado o mosteiro cisterciense feminino de Celas de Guimarães ${ }^{29}$. A Sul, na margem esquerda do rio Mondego, implantava-se, inicialmente, o Mosteiro de Celas de Além da Ponte, ou de Santana, de Cónegas Regrantes, sujeitas ao mosteiro vizinho de S. Jorge, existente já desde a segunda metade do século XII. Inspirados pelas novas correntes de espiritualidade da Europa, foram construídos durante o século XIII, ainda nessa margem do rio, os mosteiros mendicantes ${ }^{30}$ de S. Francisco e de Santa Clara e, no arrabalde Norte da cidade, implantaram-se os frades Pregadores de S. Domingos ${ }^{31}$.

Concluída a descrição do mapa institucional e eclesiástico de Coimbra medieval ${ }^{32}$, passamos ao objecto deste estudo, ou seja, à caracterização das freguesias da cidade através da identificação, em cada uma delas, dos edifícios, estruturas e equipamentos diferenciadores da sua paisagem ${ }^{33}$. Partindo do

${ }^{29}$ Sobre este mosteiro ver Maria do Rosário Morujão, Um Mosteiro Cisterciense Feminino: Santa Maria de Celas: séculos XIII a XV, Coimbra, Biblioteca Geral da Universidade, 2001.

${ }^{30}$ Sobre a implantação dos institutos mendicantes em Coimbra, ver Saul António Gomes, "As ordens mendicantes na Coimbra medieval: notas e documentos", Lusitania Sacra, 10, $2^{\mathrm{a}}$ série (1998) pp. 149-215.

${ }^{31}$ Sobre a influência e o estabelecimento dos frades pregadores em Coimbra, ver Maria Helena da Cruz Coelho e João José da Cunha Matos, "O Convento Velho de S. Domingos de Coimbra. (Contributo para a sua história)", Arquivo Histórico Dominicano Português, III/2 (1986), pp. 1-13 e Saul António Gomes, "A Igreja de S. Domingos de Coimbra em 1521", Arquivo Coimbrão. Boletim da Biblioteca Municipal. XXXIX (2006) pp. 377-396.

${ }^{32}$ Para além das outras obras, oportunamente citadas no decorrer deste artigo, sem qualquer objectivo de inventariação exaustiva da produção historiográfica sobre o tema, remetemos o leitor para alguns dos títulos que poderão permitir um melhor confronto da realidade de Coimbra e de outras cidades nacionais coevas: A. H. de Oliveira Marques, Iria Gonçalves e Amélia Aguiar Andrade (coord.), Atlas de Cidades Medievais Portuguesas: séculos XII-XV, Lisboa, Centro de Estudos Históricos da Universidade Nova, INIC, 1990; Maria João Violante Branco Marques da Silva, Aveiro Medieval, Aveiro, Câmara Municipal, 1991; Ana Maria S. A. Rodrigues, Torres Vedras: a vila e o termo nos finais da Idade Média, Lisboa, Fundação Calouste Gulbenkian, JNICT, 1995; Manuela Santos Silva, Estruturas Urbanas e Administração Concelhia: Óbidos medieval, Cascais, Patrimonia, 1997; Amélia Aguiar de Andrade, Horizontes Urbanos Medievais, Lisboa, Livros Horizonte, 2003; Maria de Fátima Botão, A construção de uma identidade urbana no Algarve Medieval: o caso de Loulé, Casal de Cambra, Caleidoscópio, 2009; Maria da Conceição Falcão Ferreira, Guimarães: “duas vilas, um só povo”: estudo de história urbana (1250-1389), Braga, s.n., 2010.

${ }^{33}$ Sobre o estudo da paisagem antiga e medieval, conquanto mais se relacione com os seus aspectos agrários e rurais, propomos a leitura de Gérard Chouquer, Monique Clavel-Levêque e François Favory, "Cadastres, occupations du sol et paysages agraires antiques", Annales, Économies, Sociétés, Civilisations, 5-6 (1982) pp. 847-882 (http://www.persee.fr/web/revues/ home/prescript/article/ahess_0395-2649_1982_num_37_5_282908 consultado em 2011.02.22) e Gérard Chouquer, Quels scénarios pour l'histoire du paysage?: orientations de recherche pour 
reconhecimento dos elementos dominantes na sua malha urbana, como sejam, a igreja paroquial, o seu adro e os principais eixos viários que para ela confluíam, destacaremos a existência de parcelas de propriedade com aptidões agrárias e de implantações com carácter utilitário e funcional, tais como os equipamentos de transformação de produtos alimentares, de abastecimento de água e as construções para o armazenamento de cereal. Este percurso terá como objectivo pôr em evidência as edificações que se podiam distinguir no tecido urbano medieval pela diversidade de funções que lhes estavam associadas. Abstemo-nos, porém, de identificar e caracterizar a a presença e disposição mais comum e contínua do casario ${ }^{34}$.

No interior da cerca coimbrã, tinham lugar cinco paróquias: Sé, S. Pedro, S. Cristóvão, S. João de Almedina e S. Salvador. Pormenorizemos a paisagem desta urbe, através de algumas imagens que até nós chegaram das suas freguesias na Baixa Idade Média.

A paróquia da $\mathrm{Se}^{35}$, no centro da Almedina, tinha o seu núcleo no adro da catedral, ocupado por um conjunto de casas que serviriam de residência aos seus cónegos. Era para este espaço que convergiam, os dois pontos comerciais da Alta, configurados pelas ruas das Tendas e das Fangas ${ }^{36}$. Como já atrás se disse, era ainda aqui que se reunia o concelho da cidade, num local que, desde o século XII, vem registado na documentação com um vocabulário que assinala o seu carácter de espaço forense público ${ }^{37}$. Numa das mais antigas paróquias da cidade, onde se polarizava o poder religioso e também o poder político concelhio, encontramos, em tempos medievos, referências a cortinhais e a oliveiras, bem como a uma cisterna ${ }^{38}$.

l'archéogéographie: essai, Coimbra e Porto, Centro de Estudos Arqueológicos das Universidades de Coimbra e Porto, 2007, destacamos desta obra o capítulo 20 da $5^{\text {a }}$ parte subordinado ao tema "Les dynamiques médiévales".

${ }^{34}$ Sobre as estruturas habitacionais da cidade medieval portuguesa, ver Luísa Trindade, A Casa Corrente em Coimbra: Dos finais da Idade Média aos inicios da Época Moderna, Coimbra, Câmara Municipal, 2002 e Idem, O Urbanismo..., cit., pp. 177-195.

${ }^{35}$ Para o estudo das origens e história institucional da Sé de Coimbra, entre os outros estudos já citados, cfr. Maria Helena da Cruz Coelho, "Nos Alvores da História de Coimbra: D. Sesnando e a Sé Velha" in Sé Velha de Coimbra. Culto e Cultura. Ciclo de Conferências, Coimbra, Catedral de Santa Maria, 2005.

${ }^{36}$ «...em si mesmas sobrevivências, por certo, de comerciantes e artesãos muçulmanos instalados na Medina», ver Maria Helena da Cruz Coelho, "Coimbra Trecentista ...”, cit., p. 337.

${ }^{37}$ Cfr. Saul António Gomes, "Coimbra: Aspectos...", cit., p. 138.

${ }^{38}$ Cfr. Carla Patrícia Rana Varandas, A Colegiada de S. Pedro de Coimbra das Origens ao Fim do Século XIV. Estudo Económico e Social, Coimbra, Faculdade de Letras, 1999 (tese de mestrado policopiada), pp. 55 e 56. 
No espaço limítrofe com o da paróquia de Santa Maria da Sé, num nível topográfico mais elevado, que corresponderia ao antigo forum romano ${ }^{39}$, localizava-se a paróquia de $\mathrm{S}$. João de Almedina ${ }^{40}$ onde se situava, desde muito cedo, o paço episcopal. A toponímia desta paróquia dá-nos ecos possíveis acerca da paisagem que a configurava: nela se situava a Rua das Covas, que atestaria a existência de celeiros para armazenar cereal ${ }^{41}$.

O complexo arquitectónico de S. João de Almedina seria constituído por uma igreja cuja fachada abria para um atrium correspondente ao antigo forum romano e a Norte da igreja localizar-se-ia o claustro. Deste núcleo até à rua de S. Salvador, fixavam-se as hortas, cavalariças, forno de pão, pombal e instalações dos criados - estruturas que permitiriam uma certa autonomia funcional aos aposentos do bispo ${ }^{42}$. Este agrupamento de espaços e edifícios multifacetados que se caracterizavam pela aglutinação, num mesmo recinto, de valências residenciais, funcionais e de produção, localizados na cerca da cidade, verificava-se na casa de outros senhores eclesiásticos portugueses. Sabemos, por exemplo, que o arcebispo de Braga, mantinha casas com quintais na alcáçova de Santarém ${ }^{43}$.

Junto a esta paróquia, implantava-se a de S. Salvador, cuja igreja existia já à data da segunda reconquista cristã de Coimbra ${ }^{44} \mathrm{e}$ à qual esteve ligada, até ao segundo terço do século XII, a comunidade moçárabe ${ }^{45}$. Pouco pudemos apurar acerca da sua paisagem, para além de alguns traços sobre a sua configuração no século $\mathrm{XI}^{46}$.

${ }^{39}$ Cfr. Jorge de Alarcão, Coimbra. A Montagem ..., cit., p. 104.

${ }^{40}$ Ver Vergílio Correia e António Nogueira Gonçalves, Inventário Artístico de Portugal. Cidade de Coimbra, vol. II, Lisboa, Academia Nacional de Belas Artes, 1947, p. 27. Jorge de Alarcão afirma que esta igreja estaria a ser reedificada em 1087 e que em 1160 se projectava uma nova edificação: ver Jorge de Alarcão, Coimbra. A Montagem ..., cit., pp. 105 e 127.

${ }^{41}$ Ver Saul António Gomes, “Coimbra: Aspectos...", cit., p. 141. Existem, porém, outras explicações para este topónimo: António de Vasconcelos considerou que se referiria às sepulturas abertas no adro da Sé e Ferraz de Carvalho defendeu ser este uma alusão às ruínas do criptopórtico que porventura aí se teriam descoberto: ver Jorge de Alarcão, “As Origens...”, cit., p. 34.

${ }^{42}$ Cfr. Idem, Coimbra. A Montagem..., cit., p. 128.

${ }^{43}$ Cfr. Maria Ângela Beirante, Santarém Medieval, Lisboa, Universidade Nova, Faculdade de Ciências Sociais e Humanas, 1980, p. 63.

${ }^{44}$ Cfr. Ibidem, p. 109.

${ }^{45}$ Cfr. Leontina Ventura, "Coimbra Medieval:...", cit., p. 17. Sobre esta igreja veja-se Eduardo Proença Mamede, "Igreja do Salvador. (Subsídios para o seu Estudo)", Munda, 20 e 21 (1990/1991) pp. 23-39 e 3-6.

${ }^{46}$ Cfr. Jorge de Alarcão, Coimbra. A Montagem ..., cit., pp. 109 e 110. 
Entre o Castelo e a Alcáçova encontrava-se a paróquia de S. Pedro ${ }^{47}$, polarizada em torno da igreja e do seu adro, onde se situavam algumas habitações e, pelo menos, uma torre no exterior do templo ${ }^{48}$. Os seus fregueses seriam, na sua maioria, funcionários do concelho, da administração e da justiça régia, tabeliães e escrivães, sendo ainda preponderante a presença dos eclesiásticos ${ }^{49}$.

No século XIV, o estudo dos contratos de exploração de propriedade desta igreja revela que esta freguesia continuava a ter um cunho bastante rústico. As rendas acessórias, remíveis em ovos, pressupunham a existência de capoeiras $^{50}$ e vários contratos denunciavam a configuração de casas com cortinhais $\operatorname{anexos}^{51}$. Junto à colegiada de $\mathrm{S}$. Pedro, está documentada a existência de uma adega e de dois celeiros ${ }^{52}$. Ainda nesta paróquia, mas junto ao castelo da cidade identificamos, na entrada de Trezentos, outras casas com quintais e, entre este e a porta do Sol, a igreja detinha um campo com árvores de fruto ${ }^{53}$. Já no século $\mathrm{XV}$, encontramos os procuradores do concelho a aforar, junto desta igreja, um chão cujas confrontações atestam a proximidade de quatro cortinhais ${ }^{54}$.

No extremo Sul da Almedina - entre a Porta da Genicoca e a de Belcouce localizava-se a paróquia de $\mathrm{S}$. Cristóvão ${ }^{55}$. Como nas outras paróquias, também esta tinha um núcleo constituído pela igreja paroquial e adro com algumas casas $^{56}$. Através da sua propriedade urbana, nas fronteiras da demarcação paroquial, junto das portas acima referidas, reconhecemos a presença de casas com quintais e de cortinhais ${ }^{57}$.

${ }^{47}$ Sabemos da sua existência já no século $X$, podendo remontar ao período visigótico. Cfr. Carla Patrícia Rana Varandas, A Colegiada de S. Pedro..., cit., pp. 8-10. Terá sido reedificada no século XII, seguindo o estilo artístico que se identificou como românico conimbricense do período condal, cfr. Vergílio Correia e António Nogueira Gonçalves, Inventário..., cit., pp. 25 e 26.

${ }^{48}$ Cfr. Carla Patrícia Rana Varandas, A Colegiada de S. Pedro..., cit., pp. 11 e 12.

${ }^{49}$ Cfr. Ibidem, pp. 106-110.

${ }^{50}$ Cfr. Ibidem, pp. 52 e 53.

${ }^{51}$ Cfr. Ibidem, doc. 21 e 85.

${ }^{52}$ Cfr. Ibidem, p. 56.

${ }^{53}$ Cfr. Ibidem, pp. 55 e 60 e docs. 21 e 22.

${ }^{54}$ Ver Luísa Trindade, A Casa Corrente..., cit., p. 126.

${ }^{55}$ A igreja românica de S. Cristóvão terá sido iniciada antes de 1169 e as suas obras decorriam ainda nos finais de 1180: cfr. João da Cunha Matos, A Colegiada de São Cristóvão de Coimbra (sécs. XII e XIII), Tomar, 1998 (policopiada). Sobre esta igreja, ver Manuel Luís Real, "A Colegiada de S. Cristóvão de Coimbra e seus Capitéis", in Estudos de Arte e História. Estudos em Homenagem a Artur Nobre de Gusmão, Lisboa, Vega, 1995, pp. 207-217; Lígia Inês Gambini, Teatro Sousa Bastos. As Primeiras Décadas de História, Coimbra, CCRC, 1999.

${ }^{56}$ João da Cunha Matos, A Colegiada..., cit., p. 30.

${ }^{57}$ Ver Ibidem, doc. 125 e 131. 
A implantação na cerca da cidade destes espaços de aptidões agrícolas, de aprovisionamento de água e de armazenamento de cereais serviria de resposta às necessidades de abastecimento dos seus habitantes e instituições. Estratégia que se pode atestar para outras cidades nacionais. Neste sentido, por exemplo, no século XIV, também a colegiada de Santa Maria, em Santarém, fazia localizar na alcáçova os seus celeiros ${ }^{58}$, do mesmo modo que a Sé de Évora detinha o mesmo tipo de edifícios, nas suas imediações ${ }^{59}$.

Por outro lado, julgamos que estas estruturas poderiam corresponder, em Coimbra, a vestígios de uma anterior organização urbanística caracterizada pelas cortes $^{60}$ - propriedades cercadas, constituídas por um conjunto de edifícios que concorriam para a autonomia funcional destas unidades de residência familiar de gente de vulto ${ }^{61}$.

Todavia, no período tardo-medieval estes espaços também denunciavam uma cidade que perdia densidade populacional. A este nível, devemos ter em consideração duas realidades distintas: em primeiro lugar, o decréscimo demográfico que se fez sentir em toda a região, nas centúrias de Trezentos e Quatrocentos ${ }^{62}$ e, seguidamente, o despovoamento da Almedina em favor do arrabalde, paulatinamente, verificado desde séculos anteriores. Das variadas razões que desencadearam este último processo, que nesta fase do estudo mais nos interessa desenvolver, destacamos, por um lado, a partir de meados do século XII, o clima de paz e estabilidade que os recuos do inimigo muçulmano proporcionavam a uma população que, por isso, preteria a segurança da muralha

${ }^{58}$ Cfr. Maria Ângela Beirante, Santarém..., cit., p. 63.

${ }^{59}$ Cfr. Maria Ângela Beirante, Évora na Idade Média, Lisboa, Fundação Calouste Gulbenkian, JNICT, 1995, p. 60.

${ }^{60}$ Jorge de Alarcão (Coimbra. A montagem..., p. 140) define cortes, da seguinte forma: «residência de gente de bastantes posses - os nobiles ou maiori - e com quintal ou quinta, nalguns casos de grandes dimensões».

${ }^{61}$ As cortes seriam uma realidade urbanística até, pelo menos, ao século XII, cfr. Leontina Ventura, "As Cortes ou a instalação em Coimbra dos fideles de D. Sesnando" in Estudos em Homenagem ao Professor Doutor José Marques, vol. III, Porto, Faculdade de Letras, 2006, pp. 37-52. A autora assinala a distribuição destas cortes pelos homens de confiança de D. Sesnando, nas proximidades da Sé de Coimbra, tão bem como das igrejas de S. Salvador e de S. João de Almedina.

${ }^{62}$ A densidade populacional da região de Coimbra na Idade Média evidenciou, de uma forma geral, um período de expansão demográfica nos séculos XII e XIII que deu lugar, nas centúrias de Trezentos (a partir da última década da sua primeira metade) e Quatrocentos, a uma forte contracção. Para um conhecimento mais detalhado destes ritmos e da multiplicidade de factores que lhes deram origem, ver Maria Helena da Cruz Coelho, O Baixo Mondego ..., cit., pp. 12-23 e 26-38. 
pelo espaço mais amplo do seu exterior ${ }^{63}$, por outro, na centúria seguinte, o afastamento da corte e o consequente desaparecimento das estruturas e serviços que a apoiavam ${ }^{64}$.

O esvaziamento dos recintos muralhados foi, de resto, uma realidade observável em todo o contexto nacional. Por exemplo, em Santarém, o despovoamento da alcáçova, nos inícios do século XV, era denunciado pela identificação, nesse espaço, de cortinhais, árvores de fruto e parreiras entre ruínas de casas e pardieiros ${ }^{65}$. Perante esta tendência, os monarcas, para quem o povoamento desses núcleos era essencial à manutenção das infra-estruturas defensivas, reagiram incentivando a sua ocupação e dinamização ${ }^{66}$.

Em Coimbra, registamos um exemplo desses incentivos que envolveu a determinação da localização da feira. Inicialmente, sabemos da existência de um mercado semanal, pelo menos a partir do ano de 1269, que se realizava nas casas do rei, situadas na cidade Alta ${ }^{67}$. Em 1377, D. Fernando concedeu uma feira franca anual que deveria ocorrer no curral dos paços régios ${ }^{68}$. Quer num caso, quer noutro - com D. Afonso III e posteriormente no reinado Fernandino - os monarcas fizeram por implementar esta actividade na Almedina, num esforço continuado, de não permitir a desvitalização deste espaço. Porém, as dificuldades de deslocação dos mercadores com as suas bestas e de transporte dos produtos, num intramuros íngreme e irregular, levaram a que, nos dois casos - por vontade das gentes e mediação do concelho - a feira fosse deslocada para fora de portas $^{69}$.

Neste último reinado, conhece-se a concessão de numerosas regalias desta natureza um pouco por todo o país. No caso de Coimbra estas seriam ainda reforçadas, quase um século depois, pelo infante D. Pedro, mas só a fixação definitiva da Universidade nesta cidade acabaria por, de alguma forma, reanimar o espaço intramuros ${ }^{70}$.

${ }^{63}$ Cfr. Luísa Trindade, A Casa Corrente..., cit., p. 128.

${ }^{64}$ Ver António Filipe Pimentel, A Morada da Sabedoria. O paço real de Coimbra das origens ao estabelecimento da Universidade, Coimbra, Almedina, 2005, p. 255.

${ }^{65}$ Cfr. Maria Ângela Beirante, Santarém..., cit., p. 64.

${ }^{66}$ Ver Luísa Trindade, Urbanismo..., cit., p. 164.

${ }^{67}$ Cfr. Maria Helena da Cruz Coelho, A Feira de Coimbra no Contexto das Feiras Medievais Portuguesas, Coimbra, Inatel, 1994, p. 20.

${ }^{68}$ Cfr. Ibidem, p. 23.

${ }^{69}$ Cfr. Ibidem, p. 21 e 24.

${ }^{70}$ Cfr. Luísa Trindade, A Casa Corrente..., cit., pp. 127-128. 
Observemos agora os arrabaldes da cidade. A Sudoeste do espaço extramuros de Coimbra, junto ao rio, tinha lugar o bairro de $\mathrm{S}$. Bartolomeu ${ }^{71}$. Dentro desta paróquia, aproveitando a proximidade das águas do rio ${ }^{72}$, que serviam de força motora dos engenhos e permitiam o escoamento de detritos e a lavagem dos diferentes materiais, tinham lugar vários mesteres.

Entre a propriedade contratada por esta igreja, encontramos a referência a dois lagares de azeite, junto à Rua da Ponte ${ }^{73}$. Nos processos relativos aos dízimos que esta igreja auferia, reconhecemos profissões como as de oleiros de telha e de lagareiros de azeite ${ }^{74}$. Para a Baixa Idade Média, sobressaíam, dentre os locatários dos seus prédios, os homens de mesteres - alfaiates, seleiros e sapateiros - e os clérigos. Surgiam também alguns representantes do funcionalismo régio, bem como, barqueiros e pescadores ${ }^{75}$. Também aqui a presença de parcelas de cultivo agrícola seria significativa na medida em que, entre os seus fregueses, encontramos almuinheiros ${ }^{76} \mathrm{e}$ que, nos finais do século XIV, identificamos a implantação de vários cortinhais junto ao actual Largo do Romal ${ }^{77}$.

Em direcção ao Norte, entre a freguesia de S. Bartolomeu e o Mosteiro de Santa Cruz, situava-se a paróquia de $\operatorname{Santiago}^{78}$. A igreja localizava-se no lugar de Coruche que dava o nome à sua rua mais central ${ }^{79}$ e que tem sido caracterizada como um importante ponto comercial da cidade. Na verdade, a Rua de Coruche era disputada por mercadores, tabeliães e ourives que aí

${ }^{71} \mathrm{O}$ primeiro documento que se conhece desta igreja data de 957 e firmava uma doação deste templo ao Mosteiro do Lorvão. Ver Maria Cristina Gonçalves Guardado, A Colegiada de S. Bartolomeu de Coimbra em Tempos Medievais (Das Origens aos inícios do século XIV), Coimbra, Faculdade de Letras, 1999 (dissertação de mestrado policopiada), pp. 26-38. No que diz respeito ao seu edifício, ver Augusto Nunes Pereira, "A Igreja de S. Bartolomeu de Coimbra", in Baixa de Coimbra: uma viagem no tempo. Actas do $1^{\circ}$ Encontro sobre a Baixa de Coimbra, realizado em 24 e 25 de Outubro de 1992, Coimbra, GAAC, 1995, pp. 37-42.

${ }^{72}$ Sobre o espaço onde se implantava a paróquia de S. Bartolomeu e a sua relação com o leito do rio, ver J. A. Branquinho de Carvalho, "Coimbra, ontem e hoje. A Evolução do Largo da Portagem e da Praça 8 de Maio", in Baixa de Coimbra ..., cit., pp. 25-35 e Jorge de Alarcão, Coimbra. A Montagem ..., cit., p. 148.

${ }^{73}$ Ver Maria Cristina Gonçalves Guardado, A Colegiada de S. Bartolomeu..., cit., p. 102.

${ }^{74}$ Ver Saul António Gomes, "Coimbra: Aspectos...", cit., p. 143.

${ }^{75}$ Cfr. Maria Cristina Gonçalves Guardado, A Colegiada de S. Bartolomeu ..., cit., p. 162.

${ }^{76}$ Cfr. Ibidem, doc. 19.

${ }^{77}$ Cfr. Ibidem, docs. 110 e 113.

${ }^{78}$ Sagrada a 28 de Agosto de 1206, a sua construção terá sido iniciada ainda no século XII. Sobre esta igreja ver Vergílio Correia e António Nogueira Gonçalves, Inventário..., cit., p. 31 e Walter Rossa, Divercidade..., cit., p. 280.

${ }^{79}$ Cfr. Jorge de Alarcão, Coimbra. A Montagem ..., cit., p. 150. 
situavam as suas tendas ${ }^{80}$. Nela residiam os mercadores de maior trato e os detentores da riqueza ${ }^{81}$. Todavia, não seria o comércio, a única actividade económica que aí se implantava: por uma doação de 1258, ficamos a saber da existência nesta freguesia de um forno de pão ${ }^{82}$, que, com certeza, não seria exemplo único.

Nas traseiras da igreja de Santiago, entre as muralhas da cidade e a rua de Coruche, pelo menos até à segunda metade do século XIV, tinha lugar a judiaria, numa encosta sombria e húmida de declive acentuado ${ }^{83}$. Apartados num espaço delimitado por muralha e porta própria, as tendas e ofícios dos hebreus extrapolavam os limites da judiaria e implantavam-se no seu exterior ${ }^{84}$. Já depois da extinção da judiaria neste local, o cadastro da propriedade régia de Coimbra registava aí seis chãos - provavelmente antigas unidades de habitação entretanto abandonadas e desmoronadas - e sete cortinhais ${ }^{85}$.

Junto ao Mosteiro de Santa Cruz, dependente deste instituto monástico, implantava-se a paróquia de S. João Baptista ${ }^{86}$, cuja área foi delimitada e algumas vezes expandida em detrimento de algum espaço anteriormente adscrito às paróquias de Santiago e Santa Justa, suas vizinhas mais antigas ${ }^{87}$. Na saída Norte de Coimbra, localizava-se a freguesia de Santa Justa ${ }^{88}$, cuja rua

${ }^{80}$ Esta rua será conhecida, até quase aos nossos dias, por Rua dos Ourives: cfr. José Pinto Loureiro, Toponímia de Coimbra, vol. I, Coimbra, Câmara Municipal, 1964, p. XXVII.

${ }^{81}$ Cfr. Maria Helena da Cruz Coelho, "Coimbra Medieval:...", cit., pp. 37 e 38 e Idem, "Homens e Negócios" in Ócio e Negócio em Tempos Medievais, Coimbra, Inatel, 1998, pp. $127-$ -202. No segundo estudo, a autora analisa o percurso e herança de Estêvão Domingues, mercador de panos importados, residente nas imediações da igreja de Santiago e seu freguês.

${ }^{82}$ Ver João da Cunha Matos, A Colegiada de S. Cristóvão..., cit., p. 32 e doc. 88.

${ }^{83}$ Cfr. Jorge de Alarcão, Coimbra. A Montagem ..., cit., pp. 151-153.

${ }^{84}$ Saul António Gomes, A Comunidade Judaica de Coimbra Medieval, Coimbra, Inatel, 2003, p. 19.

${ }^{85}$ Dados colhidos da análise do Almoxarifado de Coimbra elaborado em 1395: ver Luísa Trindade, A Casa Corrente..., cit., pp. 125-126.

${ }^{86}$ Sobre a constituição desta paróquia ver Armando Alberto Martins, O Mosteiro de Santa Cruz ..., cit., pp. 248-251.

${ }^{87}$ A primeira delimitação da paróquia de Santa Cruz foi feita em Junho de 1139. Ver Leontina Ventura e Ana de Santiago Faria (ed.), Livro Santo de Santa Cruz de Coimbra. Cartulário do Século XII, Coimbra, INIC, 1990, p. 23.

${ }^{88}$ A primeira invocação que se conhece de um templo dedicado a Santa Justa data de 1098 , cfr. Walter Rossa, Divercidade..., cit., pp. 284 e 285. Em 1102 o templo de Santa Justa foi doado pelo bispo de Coimbra, D. Mauricio, ao priorado da Caridade de Cluny. Durante toda a Idade Média, Santa Justa, que entretanto se constituirá como colegiada, fará parte do padroado do Mosteiro de S. Pedro de Rates que havia sido doado, pela mesma altura, ao mesmo priorado: cfr. Avelino de Jesus da Costa, A Ordem de Cluny em Portugal, Braga, Cenáculo, 1948 e Idem, "A Ordem de Cluny em Portugal", Mensageiro de S. Bento, s.n (s.d). 
principal, de Figueira Velha, se inseria no traçado do eixo viário que ia para o Porto ${ }^{89}$.

O estudo da propriedade pertencente a estas igrejas paroquiais está ainda por ser feito ${ }^{90}$. No entanto, os poucos dados que a documentação já tratada nos dá e o conhecimento das características do solo nesta zona, remetem-nos para a visão de um espaço fortemente ruralizado.

Nos inícios do século XII, esta zona da cidade demonstrava algum povoamento, que a fixação do Mosteiro de Santa Cruz vai, de certa forma, moderar $^{91}$. Na encosta fronteira, próxima deste mosteiro, com o nome de Monte Rubeo - Montarroio - configurava-se um espaço de aptidões agrícolas, que apresentava vários prédios rústicos afectos à produção de azeite, de fruta e de vinho ${ }^{92}$. A Oriente, a paróquia de Santa Cruz apresentava a zona da Ribela, também ela destinada à implantação de várias culturas agrícolas ${ }^{93}$.

Ao local onde se fixava a colegiada de Santa Justa chama-se Arnado, denunciando-se o carácter arenoso de um solo que, naquele tempo, era a margem do rio ${ }^{94}$. Neste espaço de condições difíceis à edificação, fixaram-se durante o período medieval, vários mesteres, relembrados por uma toponímia que retratava a diferenciação ocupacional das gentes da cidade ${ }^{95}$. Em 1370 a judiaria de Coimbra foi transferida para esta zona. Do estudo sobre os bens da comunidade hebraica, podemos perceber que, nos finais do século XIV e durante todo o século seguinte, aí permaneceram estruturas como os cortinhais e os pomares ${ }^{96}$.

Nos inícios do século XIII, construía-se na fronteira Norte deste espaço o Mosteiro dos Frades Pregadores que - pertencentes à corrente mendicante, praticando o ideal de pobreza e fazendo do exemplum uma das suas vias de

${ }^{89}$ Cfr. Maria Cristina Gonçalves Guardado, A Colegiada de S. Bartolomeu ..., cit., p. 100.

${ }^{90}$ Encontramo-nos, presentemente, a realizar uma tese de doutoramento, com a orientação da Senhora Prof. ${ }^{a}$ Doutora Maria Helena da Cruz Coelho, sobre a colegiada de Santa Justa de Coimbra. Quando devidamente tratada e sistematizada, a documentação produzida nesta colegiada trará informações que permitirão fazer, com maior detalhe, a caracterização desta zona da cidade.

${ }_{91}$ Jorge de Alarcão, Coimbra. A Montagem ..., cit., pp. 155 e 167.

$92 \mathrm{O}$ estudo dos bens pertencentes aos judeus revela a existência, nesta mancha da cidade (Montarroio, no Arnado e nas proximidades de Santa Cruz), de diversas unidades de produção agrícola: ver Saul António Gomes, A Comunidade Judaica..., cit., p. 12. Por exemplo, em 1223, por um contrato de compra e venda, reconhecemos aí uma vinha com lagar, ver João da Cunha Matos, A Colegiada de S. Cristóvão..., cit., doc. 61.

${ }^{93}$ Cfr. Jorge de Alarcão, Coimbra. A Montagem ..., cit., p. 173.

${ }^{94}$ Cfr. Ibidem, pp. 180-185.

${ }^{95}$ Cfr. Saul António Gomes, A Comunidade Judaica..., cit., p. 20.

${ }^{96}$ Cfr. Ibidem, pp. 26-30. 
doutrinação -, por norma, ocupavam os espaços menos privilegiados das cidades ${ }^{97}$. Por outro lado, situavam-se nesta freguesia a mancebia e a gafaria de Coimbra, dois exemplos de rejeição dos núcleos urbanos medievais que a administração da cidade procurava circunscrever num espaço próprio e afastado do centro ${ }^{98}$.

O local da primitiva igreja de Santa Justa, por causa do antigo curso do rio, era sistematicamente inundado pelas cheias, motivo pelo qual, a igreja mudará de sítio, na entrada do século XVIII. Porém, a sua localização medieval é ainda hoje denominada por Terreiro da Erva ${ }^{99}$, perpetuando-se na toponímia uma anterior paisagem de características rústicas.

Deste modo, o arrabalde de Coimbra era um local de fixação de mesteres e de configuração de parcelas de cultivo, além de equipamentos transformadores de produtos agrícolas. Características que, de resto, o enquadravam nos contornos traçados para as outras cidades nacionais. Nelas, o arrabalde constituía um espaço peculiar na medida em que conjugava características urbanas e rurais, numa periferia reveladora de estruturas e infra-estruturas muito próprias, como fossem as oficinas, os moinhos, as almuinhas, entre outros ${ }^{100}$. Em Évora, por exemplo, a análise da evolução da propriedade adquirida pela mitra e o cabido da sua catedral, entre os finais do século XIII e inícios do XIV, demonstra que, não obstante a transformação de espaços com aptidões agrícolas em construções necessárias ao povoamento da urbe, muitas parcelas se mantiveram vocacionadas para a produção hortícola e ferragial ${ }^{101}$.

Imagem por excelência deste encontro entre campo e cidade, a maioria das feiras realizava-se, também, nestes espaços extramuros ${ }^{102}$. Por outro lado, em contraste com o interior das muralhas, onde a cintura de pedra condicionava de forma determinante o espaço disponível para a edificação, no arrabalde a

${ }^{97}$ Cfr. Jacques le Goff, Por Amor das Cidades, Lisboa, Teorema, 2007, pp. 15-18.

${ }^{98}$ Sobre estes assuntos, ver Maria Ângela Beirante, "As Mancebias nas Cidades Medievais Portuguesas" e "A Gafaria de Évora", in O Ar da Cidade. Ensaios de História Medieval e Moderna, Lisboa, Colibri, 2008, pp. 7-24 e pp. 235-252, (respectivamente).

${ }^{99}$ Ver José Pinto Loureiro, Toponímia ..., cit., vol. I, pp. 17-20.

${ }^{100} \mathrm{Cfr}$. Walter Rossa, A Urbe e o Traço. Uma década de estudos sobre o urbanismo português, Coimbra, Almedina, 2002, p. 221. Conhecemos, por exemplo, os arrabaldes da cidade de Elvas através do estudo de Fernando Branco Correia, "Paisagens periurbanas da Elvas Medieval" in Olhares Sobre a História. Estudos oferecidos a Iria Gonçalves, Lisboa, Caleidoscópio, 2009, pp. 187-192.

${ }^{101}$ Fenómeno observável, quer no Arrabalde da Porta da Moura, quer no Arrabalde de S. Mamede. Cfr. Maria Ângela Beirante, Évora..., cit., pp. 68 e 73.

${ }^{102} \mathrm{Cfr}$. Amélia Aguiar de Andrade, “A Paisagem urbana medieval portuguesa: uma aproximação" in Horizontes..., cit., p. 18. 
extensão do terreno permitiria a configuração de implantações mais amplas ${ }^{103}$, como eram os rossios, terreiros e campos ${ }^{104}$.

A definição das diferentes estruturas rústicas que observámos representava, em Coimbra, como nas demais cidades portuguesas, bons exemplos de que, mesmo a viver na cidade, o Homem medieval continuava a manter um estreito contacto com a terra e com a agricultura ${ }^{105}$. Quando possível, cultivava uma almuinha, um cortinhal ou um quintal ${ }^{106}$, plantava um pomar ou algumas árvores, mantinha uma vinha ou, mesmo, um olival, pontilhando a distribuição contígua do casario citadino com courelas de cultivo hortícola ou do colorido das suas árvores de fruto ${ }^{107}$. Na verdade, a "desruralização" da cidade foi um processo despoletado, apenas, no século XIX ${ }^{108}$.

No entanto, os arrabaldes de Coimbra denotavam, também, no final do século $\mathrm{XIV}$, as consequências das guerras fernandinas que, aliadas a uma conjuntura de fome e de epidemias, reduziram drasticamente os seus níveis demográficos ${ }^{109}$. Aliás, neste contexto, o espaço exterior aos muros foi o mais fustigado pelos exércitos inimigos ${ }^{110}$, verificando-se, por isso, a desocupação e desmoronamento de muitos dos seus prédios, frequentemente, transformados, a médio prazo, em cortinhais e hortas de culturas mimosas.

Chegados ao fim da caracterização do arrabalde, damos por terminada esta pequena reflexão acerca da paisagem da urbe coimbrã medieval.

Vimos como a cidade se estruturava em dois grandes espaços: a Alta fortificada, cidade primitiva e durante todo este período conotada com as elites religiosas, políticas e militares e a Baixa, constituída pelos arrabaldes definidos, desde o século XII, como aglomerados populacionais que não deixariam de

${ }^{103}$ Cfr. Luísa Trindade, A Casa Corrente..., cit., pp. 32-38.

${ }^{104}$ Estes últimos surgem com mais frequência, a Norte do rio Douro. Ver Luísa Trindade, $O$ Urbanismo..., cit., pp. 722-726.

${ }^{105}$ Amélia Aguiar de Andrade justifica assim a presença de espaços agrícolas na malha urbana de Ponte de Lima medieval. Cfr. Amélia Aguiar de Andrade, Um Espaço Urbano Medieval: Ponte de Lima, Lisboa, Livros Horizonte, 1990, p. 72.

${ }^{106}$ Exemplo desta realidade era a frequência com que o lote habitacional contemplava a configuração de um quintal no ponto oposto à fachada que virava para a rua. Ver Luísa Trindade, O Urbanismo..., cit., p. 177.

${ }^{107}$ Cfr. Iria Gonçalves, "Entre o Campo e a Cidade na segunda metade do século XIV", in Um Olhar sobre a Cidade Medieval, Cascais, Patrimonia Historica, 1996, pp. 237-238.

${ }^{108}$ Ver Jacques le Goff, Por Amor ..., cit., pp. 30 e 31.

${ }^{109}$ Sobre a situação de Coimbra no século XIV e a forma como foi afectada por uma crise que se verificava à escala de toda a Europa, ver Maria Helena da Cruz Coelho, "Coimbra Trecentista...", cit., pp. 339-340, bem como as páginas já citadas sobre a caracterização dos ritmos demográficos da região de Coimbra em Idem, O Baixo Mondego..., cit., pp. 12-23 e 26-38.

${ }^{110}$ Cfr. Luísa Trindade, A Casa Corrente..., cit., p. 125. 
crescer. Dois espaços divididos em nove paróquias (cinco na Alta e quatro na Baixa), onde se polarizavam as gentes criando, em cada uma delas, personalidades socioeconómicas diferenciadoras.

Do percurso que realizámos pela paisagem medieval de Coimbra, ressalta a diversidade das estruturas que a compunham. Colocámos em evidência como, em cada uma das suas freguesias, se encontravam características rústicas, desde Santa Maria da Sé - pólo congregador, sede maior do poder religioso e local de reunião do município - até à paróquia de Santa Justa, na saída Norte da cidade de Coimbra, onde o espaço seria mais permeável à rusticidade envolvente. A observação dos cortinhais, das árvores de fruto e até das vinhas e oliveiras é uma constante em todo o núcleo urbano. Do mesmo modo, identificámos a implantação de equipamentos utilitários, como os lagares, os celeiros ou os fornos, necessários à economia da cidade e denunciadores de um tecido social com ocupações e actividades variadas.

Descrevemos, assim, uma convivência de espaços e estruturas diversificadas, necessária à vida da cidade e distintiva da época medieval, na qual os entrelaçamentos - económicos, sociais e culturais - sobressaíam face às individualizações e às estruturas dicotómicas. 